\title{
O PAPEL DOS TESAUROS NA INTERNACIONALIZAÇÃO DA PUBLICAÇÃO CIENTÍFICA
}

\author{
Camila Monteiro de Barros
}

Universidade Federal de Santa Catarina

\section{RESUMO}

A internacionalização da produção científica está relacionada ao intercâmbio de projetos, pesquisas em andamento e resultados de pesquisa entre nações. Em geral, as informações por meio das quais um artigo pode ser recuperado incluem: palavras do título, palavras do resumo, nome do autor, informações bibliográficas (nome do periódico, volume, edição etc.) e palavras-chave. Esse artigo tem como objetivo ressaltar especificamente a relevância do processo de escolha de palavras-chave para representação do conteúdo de publicações, chamada de indexação. Tal atividade implica limitar a complexidade do conteúdo, pois o contexto, que confere referência semântica às palavras, é drasticamente reduzido quando um termo é apresentado isoladamente. Além das variações semânticas, formais e contextuais, as variações idiomáticas das palavras adicionam uma questão fundamental para a disseminação da produção científica em contextos multilíngues como a web. Uma das soluções para aumentar a qualidade da indexação - e, em consequência, da recuperação - está na adoção de instrumentos que padronizem a terminologia, evitando assim os efeitos advindos das ambiguidades linguísticas. $O$ instrumento mais comumente utilizado no meio científico é o tesauro, que proporciona controle terminológico e semântico, sendo que a sua estrutura de relacionamento entre termos e conceitos retoma parte da sua contextualização. Além da discussão teórica, o presente artigo traz também exemplos de tesauros disponíveis na web. $\mathrm{O}$ artigo foi apresentado no V Encontro Art Research Journal e II Fórum Nacional de Editores de Periódicos da Área de Artes, realizado no Instituto de Artes da UNESP, em São Paulo, nos dias 26 e 27 de maio de 2017.

Palavras-chave: Publicação científica. Recuperação da informação. Indexação. Tesauro. 
internacionalização da produção científica está relacionada ao intercâmbio de

projetos, pesquisas em andamento e resultados de pesquisa entre nações. De acordo com Fiorin (2007), as formas tradicionais de mensurar a inserção global da pesquisa de um país incluem os seguintes aspectos: a) número de artigos publicados em revistas internacionais; b) seu impacto, determinado por meio da contagem das citações de que foram objeto; e, adicionamos ainda, c) indexação dos periódicos em bases de dados internacionais.

No que diz respeito ao primeiro e ao terceiro aspecto, algumas convenções editoriais internacionais devem ser seguidas (Comissão..., 2015): títulos de revistas comunicativos; títulos de artigos e resumos inteiramente descritivos; dados bibliográficos completos em todas as referências citadas; endereço completo para cada autor; títulos dos artigos, resumos e palavras-chave em inglês. Além desses requisitos gerais, a inclusão de um novo periódico em uma base de dados depende também da cobertura temática do periódico e sua pertinência à proposta da base.

O segundo aspecto da internacionalização envolve a quantidade de vezes que determinado artigo foi citado. Nesse sentido, podemos considerar que a facilidade ou dificuldade de recuperação de determinado artigo implica diretamente no seu fator de impacto. Em geral, as informações por meio das quais um artigo pode ser recuperado incluem: palavras do título, palavras do resumo, nome do autor, informações bibliográficas (nome do periódico, volume, edição etc.) e palavras-chave. Estas últimas são o foco desta discussão.

O processo de representar o conteúdo de um documento por meio de palavras-chave é chamado de indexação. Tal atividade implica limitar a complexidade do conteúdo, pois o contexto que confere referência semântica às palavras é drasticamente reduzido (Figura 1).

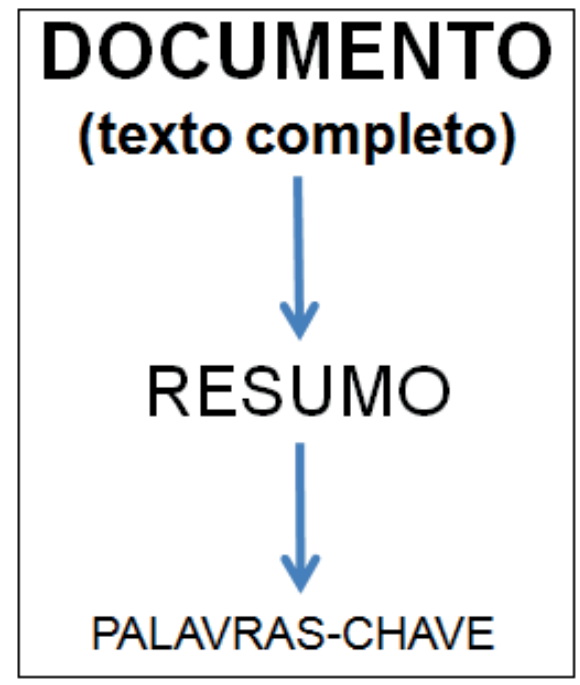

Figura 1. Redução do conteúdo do documento na representação por palavras-chave Fonte: Elaborada pelo autor. 
A ausência de contexto dificulta a transferência precisa de significado, gerando barreiras para a recuperação de documentos. Se tomarmos, por exemplo, a palavra "interpretação" no contexto da área da Música, inúmeros podem ser os significados atribuídos a essa palavra, a despeito da suposta homogeneidade da área de conhecimento: de forma geral pode ser uma "musicalidade intuitiva e exercício da imaginação na expressão de uma obra" (Sadie, 1994, p. 460); de forma mais específica no interior de uma corrente teórica como a Semiótica, "interpretação" poderia referir-se ao processo de semiose; sob outros prismas, "interpretação" pode ser entendida como um processo ou ainda um produto. Nesse caso, um pesquisador que realiza uma busca pela palavra-chave "interpretação" pode recuperar uma série de documentos que não são de seu interesse, ocultando resultados relevantes. Certo termo ser relacionado a diferentes conceitos é o que chamamos de polissemia. Ressaltamos, assim, que o compartilhamento da mesma língua e até da mesma área não garante o compartilhamento do mesmo significado (Figura 2).

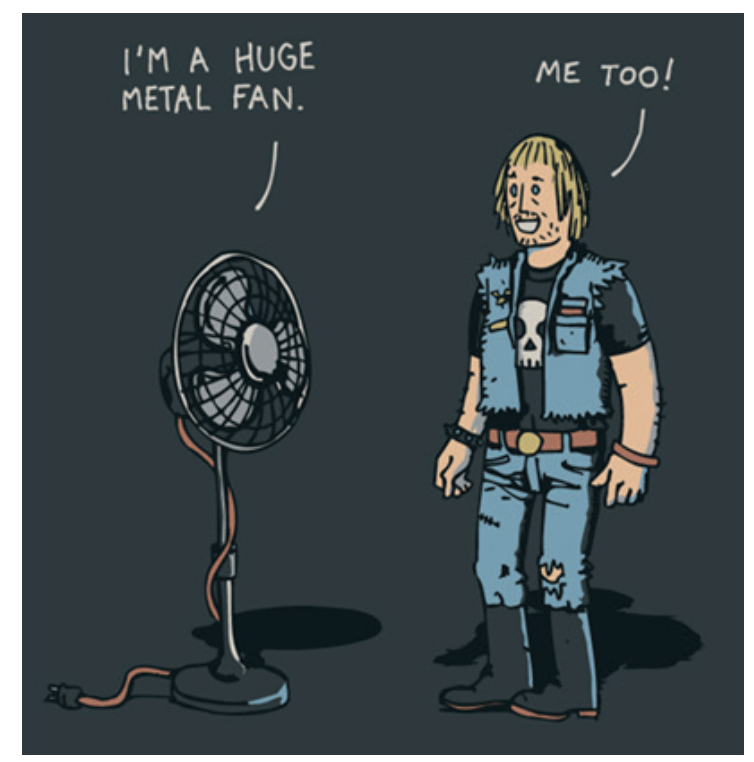

Figura 2. Linguagem $x$ Transferência de significado Fonte: Rudi (2008)

Outro problema relacionado ao significado é o de sinonímia, em que mais de um termo representa o mesmo conceito. Consideremos hipoteticamente que "interpretação" e "performance" são termos sinônimos e são utilizados na indexação de distintos documentos. Um pesquisador que realiza uma busca pela palavra-chave "interpretação" pode não recuperar diversos documentos que seriam relevantes para sua pesquisa (Figura 2). 


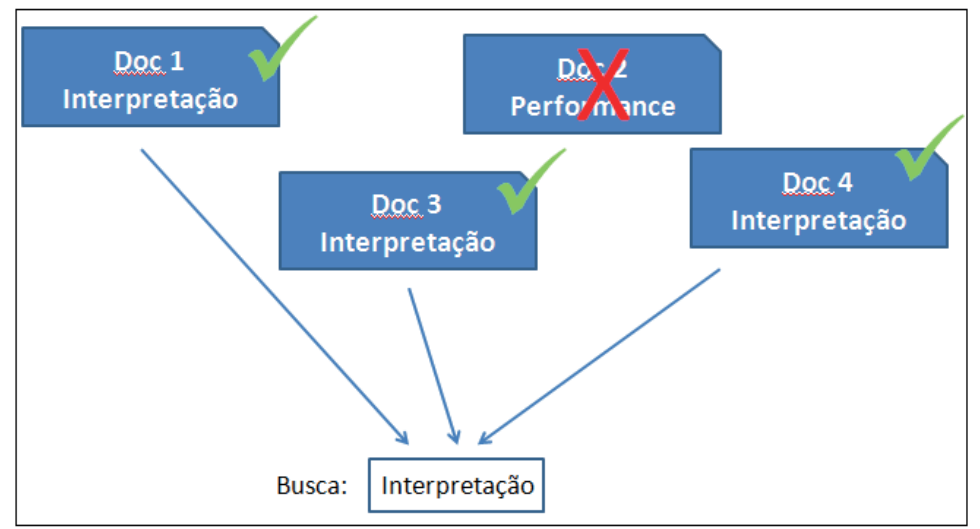

Figura 3. O problema da sinonímia na recuperação da informação Fonte: Elaborada pelo autor.

Além das variações semânticas, formais e contextuais, as variações idiomáticas adicionam uma questão fundamental para a disseminação da produção científica em contextos multilíngues como a web. Portanto, podemos considerar que, na representação de conteúdo por meio de palavras-chave, realiza-se a "tradução" (Lancaster, 2004) do conteúdo para uma forma muito sintética de descrição - que, conforme exemplos anteriores envolve variações - e também a tradução desse conteúdo sintético para outros idiomas - que, sabe-se, envolve variações culturais.

Atualmente, a maior parte dos periódicos científicos brasileiros utiliza a forma de autoarquivamento (Rodrigues; Abadal, 2014), ou seja, o próprio autor é responsável por definir as palavras-chave que melhor representam o conteúdo de seu texto. Essa prática apresenta diversas vantagens: redução de custos, especialização na representação, agilidade na publicação. Mas apresenta também algumas desvantagens: não existem parâmetros que orientem a escolha de palavras-chave (quanto à exaustividade e precisão) e nem controle terminológico do vocabulário, abrindo espaço para os problemas até agora apresentados que dificultam a recuperação da informação e a internacionalização.

Bases de dados internacionais, como a multidisciplinar Web of Science, ${ }^{1}$ utilizam as palavras-chave que constam nos artigos ou periódicos para indexá-los na base, ou seja, aqueles termos indicados pelos autores. A gestão do processo de indexação do assunto dos documentos é, portanto, realizada em âmbito local pelo periódico. $\mathrm{O}$ acesso às publicações, quantidade de citações e consequente internacionalização do periódico têm início no processo de submissão dos artigos, quando realizada a indexação. Em uma base de dados internacional, o fato de a indexação ser realizada localmente potencializa a ocorrência da polissemia e sinonímia, tendo em vista que cada periódico tem (ou não) a sua própria política de indexação.

1 Disponível em: https://www.webofknowledge.com/. Acesso em: 19 maio 2017. 
Uma das soluções para aumentar a qualidade da indexação, e em consequência da recuperação, está na adoção de instrumentos que padronizem a terminologia, evitando assim os efeitos advindos das ambiguidades linguísticas mostradas anteriormente. Neste ponto, introduzimos os sistemas de organização do conhecimento (SOC), que são "sistemas conceituais que representam determinado domínio por meio da sistematização dos conceitos e das relações semânticas que se estabelecem entre eles" (Brascher; Café, 2010); em outras palavras, são conjuntos de termos com significados determinados e relacionados. Existem diferentes tipos de SOC com estrutura e aplicações particulares, como as taxonomias, as ontologias e os tesauros. Neste espaço, falaremos apenas dos tesauros.

O tesauro é desenvolvido sempre dentro dos limites de uma área de conhecimento (é específico), os termos selecionados para compor sua estrutura devem ser representativos da área coberta e suas relações conceituais podem apresentar diferentes níveis de complexidade. O objetivo deste instrumento é o controle terminológico e semântico (Lancaster, 2004), sendo que a estrutura de relacionamento entre termos e conceitos retoma parte da sua contextualização. No tesauro poderá estar determinado, por exemplo, que sempre que determinado documento se referir à ideia de "musicalidade intuitiva e exercício da imaginação na expressão de uma obra", o termo usado para a indexação será "interpretação", independentemente do termo utilizado pelo autor do texto. Isso porque trata-se de representação de conteúdo, e não da simples transposição de palavras do texto para um sistema de gestão de publicações. Dessa forma, é possível assegurar que os textos que tratam do mesmo assunto serão recuperados sob o mesmo termo, melhorando significativamente a eficiência da recuperação da informação.

O controle terminológico proporcionado pelo uso do tesauro também apresenta vantagens e desvantagens. Como vantagem está a padronização mínima de termos, significados e suas correspondências em outros idiomas, além da melhora da recuperação, como já abordado. Como principal desvantagem está o fato de que, no sistema de autoarquivamento, é o autor que precisa realizar a tarefa de análise dos termos apropriados para representar o conteúdo da publicação e buscar sua correspondência no tesauro. Mas o uso do tesauro não incorre, necessariamente, na anulação do espaço de indexação livre (sem controle de vocabulário), que, juntamente com o resumo e informações bibliográficas, complementa a descrição do documento. Para tanto, parâmetros podem ser definidos, como número mínimo e máximo de termos controlados e de termos livres para representação de conteúdo.

A elaboração de um tesauro envolve diversas etapas: definição do escopo de abrangência (objetivos, uso, aplicação, área temática); pesquisa terminológica (levantamento das categorias, classes e termos); estabelecimento das definições (conceitos) de cada termo e das relações entre os conceitos; estruturação do tesauro. Da mesma forma, diversas são as teorias e metodologias que podem embasar cada etapa: Teoria Comunicativa da Terminologia, Linguística, Semióti- 
ca, Análise de Domínio, Teoria do Conceito etc. A elaboração de tesauro é, portanto, uma tarefa trabalhosa que exige a participação de uma equipe composta de profissionais da informação (como bibliotecários) e especialistas da área de conhecimento coberta.

Todavia, existem diversos tesauros disponíveis na web, desenvolvidos por fontes seguras, que podem ser adotados e compartilhados pelos periódicos. Um exemplo é o Tesauro de Folclore e Cultura Popular Brasileira² (Figura 4) desenvolvido pelo Centro Nacional de Folclore e Cultura Popular, ligado ao Instituto do Patrimônio Histórico e Artístico Nacional (Iphan).

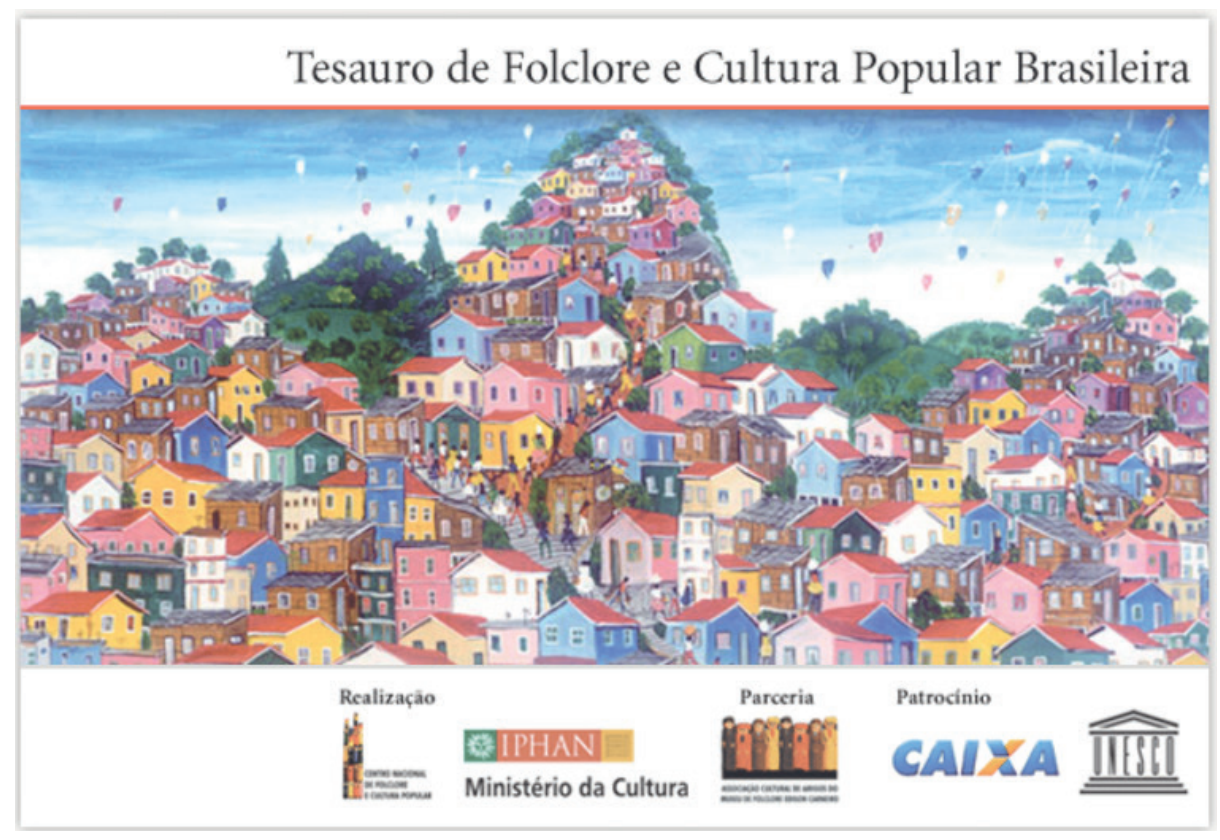

Figura 4. Página inicial do Tesauro de Folclore e Cultura Popular Brasileira Fonte: Tesauro de Folclore e Cultura Popular Brasileira

O tesauro apresenta os termos em ordem alfabética e em ordem sistemática (por categorias). Ao buscar por algum termo no tesauro, este apresenta notas explicativas sobre o contexto de uso do termo; relações hierárquicas (genérico/específico, todo/parte), associativas e de equivalências (sinônimos); além de material ilustrativo, como foto, gravação de som e vídeo (Figura 5).

2 Disponível em: http://www.cnfcp.gov.br/tesauro/. Acesso em: 16 maio 2017. 
Tesauro de Folclore e Cultura Popular Brasileira

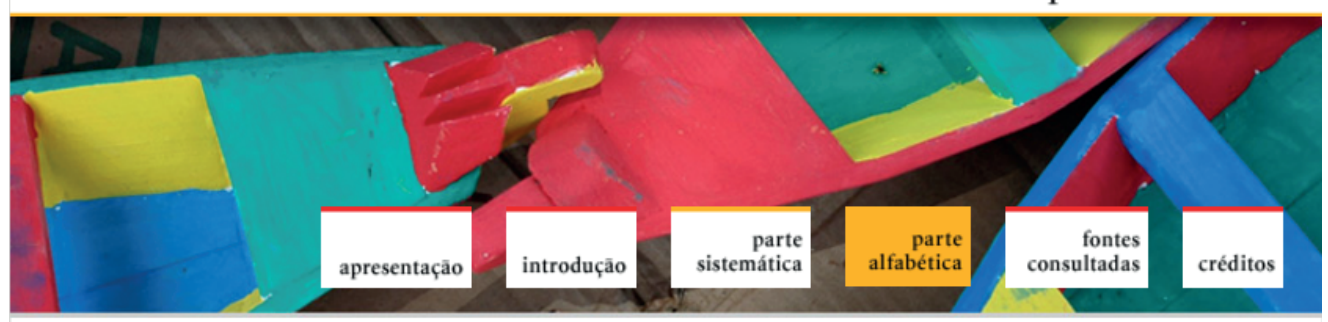

Índice

A B C D EF G

HIJKLM

NOPQR ST

U V W XY Y

Busca nos Acervos

Digitais

Busca na Internet

\section{Jongo}

Dança de conjunto com formação em círculo. No centro da roda um solista (jongueiro) puxa os cantos (pontos), que são respondidos pelo coro dos participantes, e improvisa movimentos constituídos de saltos, volteios, passos miúdos, balanceios. O instrumental é geralmente composto por dois tambores um grande (tambu ou caxambu), e um menor (candongueiro); uma puíta ou angoma-puíta (cuíca artesanal); e um chocalho (guaiá, feito de folha-deflandres ou latas usadas). O dançador-puxador permanece no centro da roda até que outro chegue diante dos instrumentos e coloque a mão sobre o tambu. A cantoria cessa imediatamente, e o antigo solista sai da roda, cedendo lugar ao outro. É geralmente dança de terreiro sem calendário fixo, podendo ocorrer em datas consideradas importantes como as festas devidas a São Benedito e São João nos estados de Minas Gerais, Rio de Janeiro e São Paulo.

Usado por

Bate-caixa

Caxambu

Termo Genérico

Dança

Termos Associados

Dança de terreiro

Danca folclórica

objetos Digitais

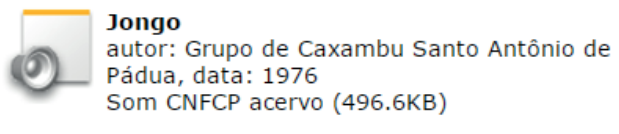

Figura 5. Relações referentes ao termo "jongo"

Fonte: Tesauro de Folclore e Cultura Popular Brasileira

As relações explicitadas pelo tesauro servem, principalmente, a dois objetivos: contextualizar os termos semanticamente e possibilitar que outros termos sejam utilizados na indexação em direção à especificação e/ou generalização do assunto do texto, ou sua associação a outros temas.

Outro exemplo, mais complexo em sua estrutura, é o Tesauro de Arte \& Arquitectura, desenvolvido pelo Getty Research Institute (GRI) e traduzido para o espanhol pelo Centro de Documentación de Bienes Patrimoniales, ligado à Diretoria de $\mathrm{Bi}$ bliotecas, Arquivos e Museus (Dibam) do Chile (Figura 6). 


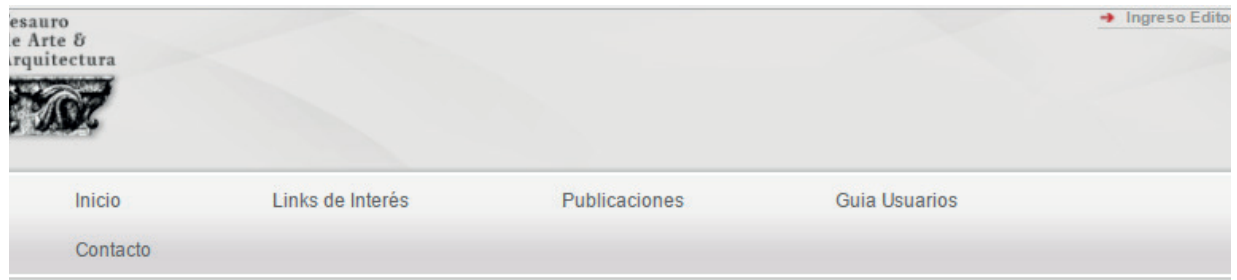

\section{El Tesauro de}

\section{Arte \& Arquitectura ${ }^{\circledR}$}

Fue desarrollado por el Getty Research Institute (GRI), un programa operativo de The J. Paul Getty Trust, y traducido en español por el Centro de Documentación de Bienes Patrimoniales (dependiente de la Dirección de Bibliotecas, Archivos y Museos - Dibam).

iil

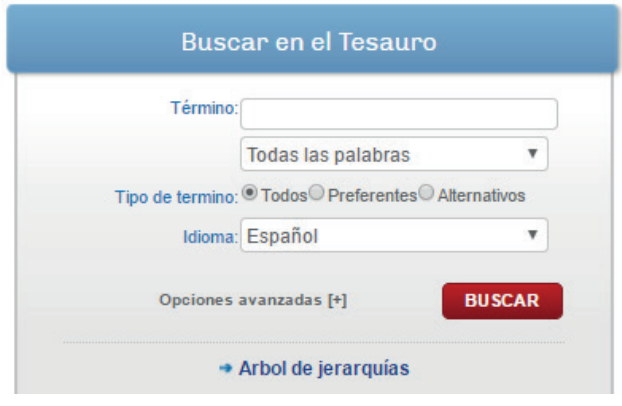

Figura 6. Página inicial do Tesauro de Arte \& Arquitectura Fonte: Tesauro de Arte \& Arquitectura

Ao buscar o termo "interpretação" no tesauro, diferentes opções são apresentadas (Figura 7). Optando por um dos termos, têm-se informações sobre seu contexto e relações (Figura 8).

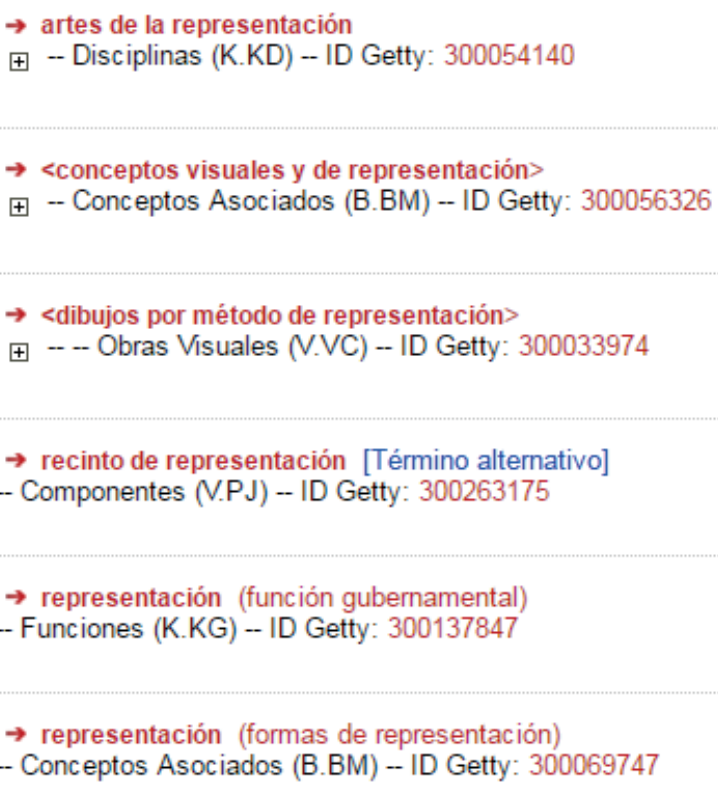

Figura 7. Resultados referentes ao termo "representación" Fonte: Tesauro de Arte \& Arquitectura 
$\rightarrow$ artes de la representación

t -Disciplinas (K.KD) - ID Getty: 300054140

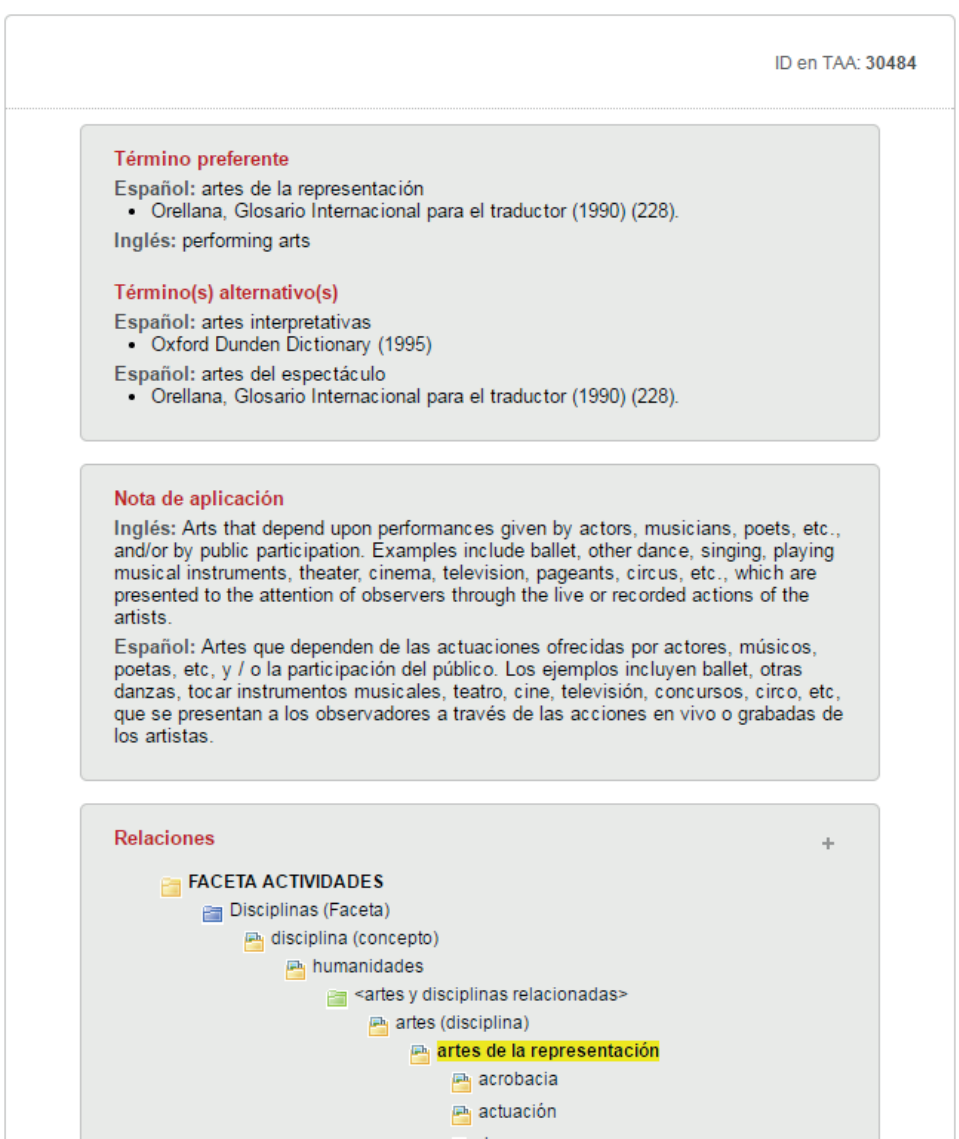

Figura 8. Especificações referentes ao termo "representación" Fonte: Tesauro de Arte \& Arquitectura

A escolha do instrumento a ser adotado na indexação vai depender das necessidades do público pesquisador (autor e usuário), das especificidades da plataforma de gestão das publicações e dos interesses do periódico na disseminação do conhecimento ali registrado.

Para que se efetive a internacionalização da publicação científica brasileira, é imprescindível trabalhar no aumento da eficiência da sua recuperação. Para tanto, considera-se, sempre, que tal eficiência está atrelada não só ao aspecto quantitativo, mas também ao aspecto qualitativo da recuperação da informação no que se refere à relação "conteúdo buscado x conteúdo recuperado". A adoção do tesauro é uma forma de aprimorar a indexação de artigos e contribuir para a disseminação do conhecimento. 


\section{Referências}

BRÄSCHER, Marisa; CAFÉ, Lígia. Organização da Informação ou Organização do Conhecimento? In: LARA, Marilda Lopes Ginez de; SMIT, Johanna Wilhelmina (Org.) Temas de Pesquisa em Ciência da Informação no Brasil. São Paulo: Escola de Comunicação e Artes/USP, 2010. p. 87-103.

COMISSÃO PARA ELABORAÇÃO DO PORTAL DE PERIÓDICOS UFSCar. Indexação de Periódicos nas bases Web of Science (WoS) e Journal Citation Reports (JCR). 2015. Disponível em: http://www.periodicos.ufscar.br/noticias/indexacao-de-periodicosnas-bases-web-of-science-wos-e-journal-citation-reports-jcr. Acesso em: 19 maio 2017.

FIORIN, J. L. Internacionalização da produção científica: a publicação de trabalhos de Ciências Humanas e Sociais em periódicos internacionais. Revista Brasileira de Pós-Graduação, v. 4, n. 8, p. 263- 281, 2007. Disponível em: http://ojs.rbpg.capes.gov. br/index.php/rbpg/article/view/133/127. Acesso em: 19 maio 2017.

LANCASTER, F. W. Indexação e resumos: teoria e prática. Brasília: Briquet de Lemos, 2004.

RODRIGUES, R. S.; ABADAL, E. Scientific Journals in Brazil and Spain: alternative publishing models. J. Ass. Inform. Science and Technology, v. 65, n. 10, p. 2145-2151, 2014. Disponível em: http://onlinelibrary.wiley.com/doi/10.1002/ asi.23115/abstract;jsessionid $=\quad$ EB2E3AE739C4C5A74D455B37349A1F28. f04t04?deniedAccessCustomisedMessage $=\&$ userlsAuthenticated $=$ false.

Acesso em: 19 maio 2017.

RUDI, Ole Ivar. Metal fan. Threadless, 2008. Disponível em: https://www.threadless. com/@OlliRudi. Acesso em: 19 maio 2017.

SADIE, Stanley (Ed.). Dicionário Grove de música. Rio de Janeiro: Jorge Zahar, 1994. TESAURO DE ARTE \& ARQUITECTURA. Disponível em: http://www.aatespanol.cl/taa/ publico/buscar.htm. Acesso em: 17 maio 2017.

TESAURO DE FOLCLORE E CULTURA POPULAR BRASILEIRA. Disponível em: http:// www.cnfcp.gov.br/tesauro. Acesso em: 16 maio 2017. 